\title{
PENGARUH TRUST, RISK AND TECHNOLOGY ACCEPTANCE MODELS TERHADAP KEPUTUSAN NASABAH DENGAN MINAT NASABAH SEBAGAI VARIABEL INTERVENING
}

\author{
Sri Ismulyaty \\ Wiwin Siswantini \\ Fakultas Ekonomi, Universitas Terbuka \\ srismu@ut.ac.id dan wiwin@ut.ac.id
}

\begin{abstract}
ABSTRAK
Sri Ismulyaty dan Wiwin Siswantini: Tujuan Penelitian untuk mengetahui pengaruh trust, risk and technology acceptance models, perceived case of use, perceived usefulness, perceived of credibility, terhadap minat nasabah dalam menggunakan internet banking? Dan bagaimana pengaruh minat nasabah dalam menggunakan internet banking terhadap keputusan dalam bertransaksi dengan internet banking? Serta bagaimana pengaruh minat nasabah dalam menggunakan internet banking memediasi hubungan antara trust, risk and technology acceptance models dengan keputusan dalam bertransaksi dengan internet banking?

Hasil pembahasan penelitian ini dapat di ambil kesimpulan sebagai berikut: Trust berpengaruh terhadap minat nasabah dalam menggunakan internet banking, Risk berpengaruh terhadap minat nasabah dalam menggunakan internet banking, Perceived case of use berpengaruh terhadap minat nasabah dalam menggunakan internet banking, Perceived usefullnes berpengaruh terhadap minat nasabah dalam menggunakan internet banking, Perceived of credibility berpengaruh terhadap minat nasabah dalam menggunakan internet banking, Minat nasabah dalam menggunakan internet banking berpengaruh terhadap keputusan dalam bertransaksi, Minat nasabah dalam menggunakan internet banking dapat memediasi hubungan antara trust, risk and technology acceptance models dengan keputusan dalam bertransaksi dengan internet banking.
\end{abstract}

\begin{abstract}
Sri Ismulyaty dan Wiwin Siswantini: The purpose of this study was to determine the influence of trust, risk and technology acceptance models, perceived case of use, perceived usefulness, perceived of credibility, the customers' interest in using internet banking? And how to influence customers' interest in using internet banking to the decision in dealing with internet banking? As well as how to influence customers' interest in using internet banking mediates the relationship between trust, risk and technology acceptance models with decisions in dealing with internet banking?

Discussion of the results of this study can be drawn the following conclusions: Trust affect the customers' interest in using internet banking, Risk affect the customers' interest in using internet banking, Perceived case of use affect the customers' interest in using internet banking, Perceived usefullnes affect the interest of the customer in using internet banking, Perceived of credibility affect the customers' interest in using internet banking, interest customers in using internet banking influence the decision in the transaction, interest customers in using internet banking may mediate the relationship between trust, risk and technology acceptance models with the decision in the transaction with internet banking.
\end{abstract}

Key Words: Trust, Risk And Technology Acceptance Model Keputusan Nasabah, Minat Nasabah

\section{PENDAHULUAN}

Menurut catatan WDR research, pertumbuhan pengguna internet di Indonesia mencapai 105\% per tahun dan merupakan pertumbuhan paling tinggi di antara negara-negara di Asia setelah China (Boerhanoeddin, 2003 dalam Ainur, 2007). Ada enam alasan mengapa teknologi internet begitu populer. Keenam alasan tersebut adalah internet memiliki konektivitas dan jangkauan yang luas, dapat mengurangi biaya komunikasi, biaya transaksi yang lebih rendah dapat mengurangi biaya agency, interaktif, fleksibel, dan mudah, serta memiliki kemampuan untuk mendistribusikan pengetahuan secara cepat. Konsep yang dinilai salah satunya merupakan paradigma bisnis baru adalah $e$-banking. E-banking sebagai bidang kajian yang relatif masih baru dan akan terus berkembang, e-banking berdampak besar 
pada praktek perbankan, setidaknya dalam hal penyempurnaan pelayanan dan mempermudah akses perbankan.

Bagi pihak bank, cyberbanking memberikan alternatif yang lebih efisien dibandingkan branch banking (melayani nasabah di kantor cabang). Bank juga dapat memanfaatkannya untuk keperluan implementasi strategi relationship marketing. Selain itu, bank juga bisa melayani nasabah yang lokasinya susah dijangkau atau belum dilayani dengan kantor cabang yang bersangkutan. Bagi nasabah, layanan cyberbanking memberikan sejumlah manfaat seperti hemat biaya dan waktu, transaksi relatif aman, dan melakukan berbagai transaksi secara nyaman dan fleksibel tanpa terikat waktu (misalnya membayar tagihan listrik dan telepon, memeriksa saldo, mentransfer uang, membayar tagihan kartu kredit, mengajukan kredit dan layanan lainnya).

Internet banking memberikan keuntungan bagi nasabah maupun bank. Bagi nasabah, internet banking menawarkan kemudahan dan kecepatan dalam melakukan transaksi perbankan. Keuntungan dari menyediakan layanan internet banking bagi bank adalah internet banking bisa menjadi solusi murah pengembangan infrastruktur dibanding membuka outlet ATM, contohnya klik bca saat ini telah menggantikan fungsi 160 ATM dan menghemat biaya pencetakan formulir yang harus diisi nasabah untuk bertransaksi, brosur, katalog, dan menggantinya dengan data elektronik (Sutadi, 2001 dalam Sri Maharsi, 2006). Tetapi internet banking juga membuka peluang timbulnya kejahatan menggunakan internet banking. Seberapa besar tingkat keamanan dan kerahasiaan data-data pribadi maupun keuangan dalam internet banking seringkali dipertanyakan oleh nasabah sebelum mereka memutuskan untuk menggunakan internet banking.

Untuk melihat kesuksesan dalam penerapan internet banking harus memperhatikan aspek perilaku. Aspek perilaku tersebut tercermin dalam Technology Acceptance Model yang dikembangkan oleh Davis (1986 dalam Sri Maharsi dan Yuliani Mulyadi, 2007). Konsep tersebut digunakan untuk melihat pengaruh variabel perceived ease of use (persepsi kemudahan untuk menggunakan), perceived usefulness (persepsi pada daya guna), variabel perceived of credibility (sikap pengguna) terhadap behavior intention (minat untuk menggunakan) teknologi informasi. Selain variabel tersebut yang tidak kalah penting yaitu resiko (risk) dan kepercayaan (trust) transaksi internet banking merupakan hal yang sangat dipertimbangkan dalam melakukan transaksi maya (virtual) karena jarak, kemampuan teknologi dalam memfasilitasi transaksi, layanan yang tidak bertatap muka dengan teller / customer service dan banyak hal yang dipertimbangkan nasabah bank dalam transaksi melalui online banking (Shergill dan Li, 2005). Variabel risk dan trust ditambahkan untuk melihat bagaimana perilaku nasabah bank untuk menggunakan internet banking ini. Dari latar belakang di atas maka peneliti bermaksud ingin meneliti tentang "Pengaruh Trust, Risk And Technology Acceptance Models (Tritam) Terhadap Keputusan Nasabah Dengan Minat Nasabah Sebagai Variabel Intervening”.

Berdasarkan latar belakang masalah di atas, perumusan masalah dalam penelitian ini adalah bagaimana pengaruh trust, risk and technology acceptance models, perceived case of use, perceived usefulness, perceived of credibility, terhadap minat nasabah dalam menggunakan internet banking? Dan bagaimana pengaruh minat nasabah dalam menggunakan internet banking terhadap keputusan dalam bertransaksi dengan internet banking? Serta bagaimana pengaruh minat nasabah dalam menggunakan internet banking memediasi hubungan antara trust, risk and technology acceptance models dengan keputusan dalam bertransaksi dengan internet banking?

Tujuan Penelitian untuk mengetahui pengaruh trust, risk and technology acceptance models, perceived case of use, perceived usefulness, perceived of credibility, terhadap minat nasabah dalam menggunakan internet banking? Dan bagaimana pengaruh minat nasabah dalam menggunakan internet banking terhadap keputusan dalam bertransaksi dengan internet banking? Serta bagaimana pengaruh minat nasabah dalam menggunakan internet banking memediasi hubungan antara trust, risk and technology acceptance models dengan keputusan dalam bertransaksi dengan internet banking? Kegunaan dari Penelitian ini bagi kalangan akademisi, dapat memberikan informasi secara ilmiah dan dapat dijadikan referensi penelitian selanjutnya. Sedangkan bagi pihak bank, diharapkan dapat menjadi masukan faktor-faktor apa saja yang berpengaruh terhadap minat pengguna internet banking dan keputusan bertransaksi.

Telaah Pustaka dari penelitian ini adalah tentang Pengertian Bank Menurut UU No. 10 tahun 1998 perubahan atas UU No. 7 tahun 1992 Pasal 1 ayat 2 tentang perbankan, yang dimaksud bank adalah badan usaha yang menghimpun dana dari masyarakat dalam bentuk simpanan dan menyalurkannya kepada masyarakat dalam bentk kredit dan atau bentuk-bentuk lainnnya dalam rangka meningkatkan taraf hidup rakyat banyak. Internet Banking adalah kegiatan perbankan yang dilakukan secara online dalam hal ini adalah internet banking sifatnya lebih fleksibel karena tidak diatasi ruang dan waktu, sehingga nasabah dapat menjangkau layanan perbankan dari manapun dan kapanpun. Jadi, dapat dikatakan bahwa internet banking seperti kantor cabang suatu bank yang tidak berwujud karena semua 
kegaitan di dalamnya dilakukan secara online. Persepsi Manfaat (Perceived Usefulness) internet banking merupakan manfaat yang diperoleh atau diharapkan oleh para nasabah dalam melakukan tugas dan pekerjaannya. Seseorang akan mengadopsi internet banking apabila orang tersebut mempercayai bahwa internet banking dapat memberikan manfaat terhadap pekerjaannya dan pencapaian prestasi kerjanya. Oleh karena itu, tingkat kemanfaatan internet banking mempengaruhi sikap para nasabah terhadap sistem tersebut. Persepsi Kemudahan Penggunaan (Perceived Easy of Use) adalah Pengertian perspektif memberikan indikasi bahwa suatu sistem dirancang bukan untuk menyulitkan pemakainya, akan tetapi penggunaan sistem justru mempermudah seseorang dalam menyelesaikan pekerjaannya. Dengan kata lain, seseorang yang menggunakan sistem akan bekerja lebih mudah dibandingkan dengan seseorang yang menggunakan sistem manual. Persepsi Kredibilitas (Perceived Credibility) adalah persepsi atas suatu kondisi yang dapat diberikan kepercayaan, karena memiliki kredibilitas yang baik. dalam penelitian ini, perceived crediblity adalah persepsi terhadap kredibilitas internet banking yang berhubungan dengan kepercayaa kepada perusahaan perbankan seperti reputasi, prestasi dan sebagainya. Resiko (Risk) adalah suatu keadaan uncertainty yang dipertimbangkan orang untuk memutuskan atau tidak melakukan transaksi secara online. Orang-orang benar-benar mempertimbangkan jarak dan suasana impersonal dalam transaksi online dan infrastruktur global yang banyak mengandung unsur resiko. Besarnya persepsi konsumen mengenai resiko memengaruhi besarnya kepercayaan mereka terhadap online bank dan sistem dari online bank tersebut sehingga ketika memproses informasi online, konsumen sering menganggap bahwa ada resiko yang tinggi walaupun resiko tersebut sebenarnya rendah (Mukheerjee dan Nath, 2003). Kepercayaan (Trust) pada penyelenggara transaksi online (banking/retailer/produsen) dan kepercayaan pada mekanisme operasional dari transaksi yang dilakukan. Upaya tinggi harus dilakukan oleh penyelenggara transaksi online agar kepercayaan konsumen semakin tinggi, karena trust mempunyai pengaruh besar pada niat konsumen untuk melakukan transaksi secara online atau tidak melakukannya.Minat menggunakan Internet Banking digambarkan sebagai hubungan secara online antar nasabah dan banking online. Penelitian ini mempertimbangkan minat untuk bertransaksi secara online, yaitu transfer antar rekening, pembayaran tagihan, informasi saldo, pembukaan dan penempatan deposito, dan lain sebagainya. Dalam TAM, faktor persepsi terhadap kemudahan untuk menggunakan teknologi dan persepsi terhadap daya guna sebuah teknologi berhubungan dengan sikap seseorang pada penggunaan teknologi tersebut. Sikap suka atau tidak suka terhadap suatu produk ini dapat digunakan untuk memprediksi perilaku minat seseorang untuk menggunakan suatu produk atau tidak menggunakannya.

Pengembangan Model yang digunakan dalam penelitian ini adalah model dasar dari penelitian Lui dan Jamieson (2003) serta penelitian Shergill dan Li (2005). Lui dan Jamieson menggunakan konsep TRITAM yang merupakan modifikasi dari model TAM, sedangkan Shergill dan Li meneliti mengenai faktor-faktor yang mempengaruhi trust. Berdasarkan penelitian Maharsi dan Fenny (2006) dapat diketahui Kepercayaan pengguna pada internet banking (TRU) terbukti memberikan pengaruh yang signifikan terhadap loyalitas pengguna untuk menggunakan internet banking. Berdasarkan hasil penelitian tersebut maka disusun hipotesis penelitian sebagai berikut:

$\mathrm{H}_{1}$ : Trust berpengaruh terhadap terhadap minat nasabah dalam menggunakan internet banking.

Modifikasi model TAM juga dilakukan oleh Venkantesh (2002) dengan menambahkan variabel trust dengan judul : Trust enhanced Technology Acceptance Model. Modifikasi TAM lain yaitu Trust and Risk in Technology Acceptance Model (TRITAM) yang menggunakan variabel kepercayaan dan resiko bersama variabel TAM (Lui dan Jamieson, 2003). Berdasarkan penelitian Lui dan Jamieson (2003) dapat diketahui perceived risk memiliki pengaruh terhadap intensitas untuk bertransaksi. Berdasarkan hasil penelitian tersebut maka disusun hipotesis penelitian sebagai berikut:

$\mathrm{H}_{2}$ : Risk berpengaruh terhadap terhadap minat nasabah dalam menggunakan internet banking.

Berdasarkan penelitian Lui danJamieson (2003) dapat diketahui perceived case of use dan perceived usefullnes memiliki pengaruh terhadap intensitas untuk bertransaksi. Berdasarkan hasil penelitian tersebut maka disusun hipotesis penelitian sebagai berikut:

$\mathrm{H}_{3}$ : Perceived case of use berpengaruh terhadap minat nasabah dalam menggunakan internet banking.

$\mathrm{H}_{4}$ : Perceived usefullnes berpengaruh terhadap minat nasabah dalam menggunakan internet banking. 
Berdasarkan penelitian Maharsi dan Fenny (2006) dapat diketahui Kepercayaan pengguna pada Perceived of credibility terbukti memberikan pengaruh yang signifikan terhadap loyalitas pengguna untuk menggunakan internet banking. Berdasarkan hasil penelitian tersebut maka disusun hipotesis penelitian sebagai berikut:

$\mathrm{H}_{5}$ : Perceived of credibility berpengaruh terhadap minat nasabah dalam menggunakan internet banking.

Keputusan seorang konsumen dalam melakukan transaksi dilatarbelakangi oleh minat. Setelah konsumen berminat tahap selanjutnya adalah melakukan pembelian. Berdasarkan penelitian Prabowo (2007) dapat diketahui bahwa minat berpengaruh terhadap keputusan konsumen dalam bertransaksi, sehingga dirumuskan hipotesis:

$\mathrm{H}_{6} \quad$ : Minat nasabah dalam menggunakan internet banking berpengaruh terhadap keputusa dalam bertransaksi.

Berdasarkan penelitian terdahulu dapat diketahui adanya pengaruh trust, risk and technology acceptance models terhadap minat nasabah sebagai variabel intervening dan minat berpengaruh terhadap keputusan nasabah, maka disusun hipotesis.

$\mathrm{H}_{7} \quad$ : Minat nasabah dalam menggunakan internet banking dapat memediasi hubungan antara trust, risk and technology acceptance models dengan keputusan dalam bertransaksi dengan internet banking.

Berdasarkan teori di atas, maka penulis menggunakan konsep TRITAM sehingga diperoleh kerangka pemikiran sebagai berikut:

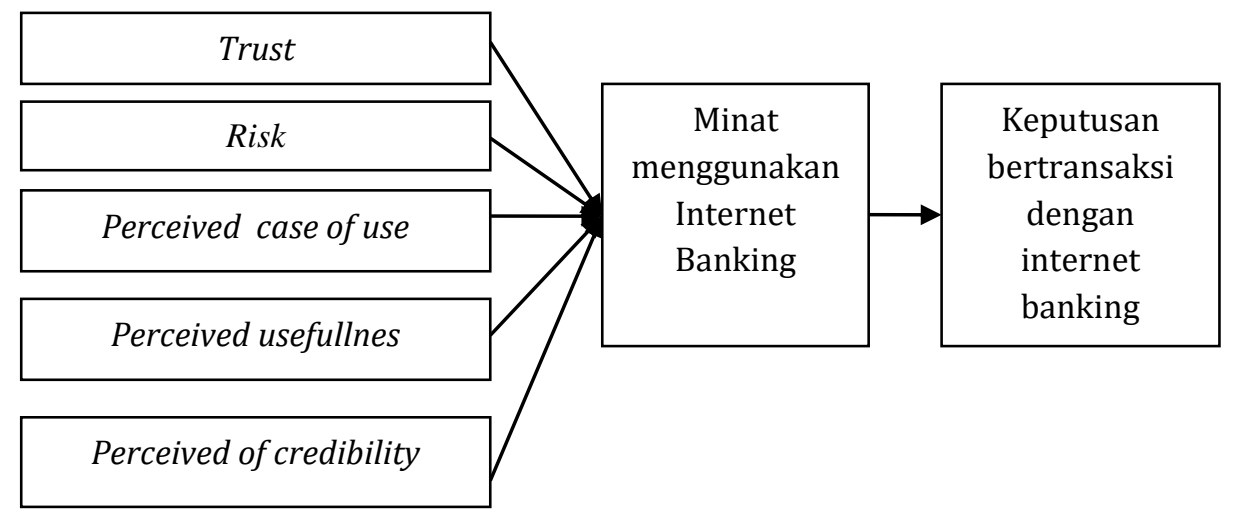

Gambar 1. Kerangka Analisis

Metode dalam penelitian ini untuk obyek dan sasaran dilakukan pada perusahaan jasa perbankan yang menerapkan internet banking dan sasarannya adalah pengguna internet banking di Jabodetabek. Jenis dan Sumber Data Penelitian ini menggunakan data primer, yaitu data yang bersumber dari responden secara langsung dari hasil pengisian kuesioner. Metode Pengumpulan data dalam penelitian ini menggunakan metode survei dengan instrumen penelitian berupa kuesioner.Populasi dan Sampel dalam penelitian ini adalah nasabah bank umum maupun swasta yang pernah menggunakan internet banking di Jabodetabek. Metode pengambilan sampel menggunakan metode accidental sampling, yaitu nasabah yang menggunakan internet banking serta mampu menjawab setiap butir pernyataan kuesioner yang diberikan dengan baik.

\section{METODE PENELITIAN}

Penelitian ini dilakukan pada perusahaan jasa perbankan yang menerapkan internet banking dan sasarannya adalah pengguna internet banking di Jabodetabek. Penelitian ini menggunakan data primer, yaitu data yang bersumber dari responden secara langsung dari hasil pengisian kuesioner. 
Pengumpulan data dalam penelitian ini menggunakan metode survei dengan instrumen penelitian berupa kuesioner.

Populasi dalam penelitian ini adalah nasabah bank umum maupun swasta yang pernah menggunakan internet banking di Jabodetabek. Metode pengambilan sampel menggunakan metode accidental sampling, yaitu nasabah yang menggunakan internet banking serta mampu menjawab setiap butir pernyataan kuesioner yang diberikan dengan baik. Teknik Analisis Data dalam penelitian ini adalah dengan cara: Pengukuran Variabel, Uji Validitas, Standardized loading, Structural Equation Modeling (SEM). Ada tujuh langkah yang harus dilakukan apabila menggunakan Structural Equation Modelling (SEM) (Ferdinand; 2005): ada tahapan-tahapannya adalah :

a. Pengembangan model teoritis

b. Pengembangan diagram alur (path diagram).

c. Konversi diagram alur ke dalam persamaan

d. Memilih matrik input dan estimasi model menggunakan matriks varians/kovarians atau matrik korelasi untuk keseluruhan estimasi yang dilakukan.

e. Kemungkinan munculnya masalah identifikasi

f. Evaluasi kriteria goodness of fit, Pada tahap yang terakhir adalah menginterpretasikan model dan memodifikasi model bagi model-model yang tidak memenuhi syarat pengujian yang dilakukan.

\section{Pengujian Hipotesis}

Pengujian hipotesis dilakukan dengan melakukan uji- $\mathrm{t}$ untuk melihat signifikansi koefisisen regresi yang dihasilkan oleh berbagai hubungan kausalitas dalam model. Pengujian mediasi dilakukan dengan prosedur yang dikembangkan oleh Sobel (1982 dalam Ghozali, 2009: 220-221) dan dikenal dengan uji Sobel (Sobel test).

Pembahasan dalam penelitian ini dapat dilihat bahwa pada Hipotesis pertama menyatakan trust berpengaruh terhadap minat nasabah dalam menggunakan internet banking. Berdasarkan hasil analisis dapat diketahui adanya pengaruh yang positif trust terhadap minat menggunakan internet banking. Hasil penelitian ini konsisten dengan penelitian Maharsi dan Fenny (2006) dapat diketahui kepercayaan pengguna pada internet banking (TRU) terbukti memberikan pengaruh yang signifikan terhadap loyalitas pengguna untuk menggunakan internet banking.

Hipotesis kedua menyatakan risk berpengaruh terhadap minat nasabah dalam menggunakan internet banking. Berdasarkan hasil analisis dapat diketahui variabel risk memiliki pengaruh yang negatif terhadap minat menggunakan internet banking, yaitu semakin tinggi risiko maka akan semakin rendah minat menggunakan internet banking. Hal ini berarti terdapat pengaruh negatif dan signifikan dari variabel risk terhadap minat menggunakan internet banking. Hasil penelitian ini ada kesesuaian dengan penelitian Lui dan Jamieson (2003) dapat diketahui perceived risk memiliki pengaruh terhadap intensitas untuk bertransaksi.

Pengujian hipotesis ketiga dan keempat merupakan pengembangan dari hasil penelitian Lui dan Jamieson (2003) dapat diketahui perceived case of use dan perceived usefullnes memiliki pengaruh terhadap intensitas untuk bertransaksi. Hipotesis ketiga dan keempat tersebut adalah perceived case of use berpengaruh terhadap minat nasabah dalam menggunakan internet banking dan perceived usefullnes berpengaruh terhadap minat nasabah dalam menggunakan internet banking. Berdasarkan hasil analisis dapat diketahui perceived case of use memiliki pengaruh yang positif terhadap minat menggunakan internet banking, yaitu semakin baik perceived case of use maka akan mengakibatkan minat menggunakan internet banking semakin tinggi. Hasil penelitian ini juga menghasilkan kesimpulan terdapat pengaruh positif dari variabel perceived usefullnes terhadap minat menggunakan internet banking, artinya semakin baik perceived usefullnes, maka minat menggunakan internet banking juga akan semakin kuat.

Hipotesis kelima menyatakan perceived of credibility berpengaruh terhadap minat nasabah dalam menggunakan internet banking. Berdasarkan hasil analisis dapat diketahui terdapat pengaruh positif dan signifikan dari variabel perceived of credibility terhadap minat menggunakan internet banking. Hasil penelitian ini ada kesesuaian dengan penelitian Maharsi dan Fenny (2006) dapat diketahui Kepercayaan pengguna pada Perceived of credibility terbukti memberikan pengaruh yang signifikan terhadap loyalitas pengguna untuk menggunakan internet banking.

Hipotesis keenam menyatakan minat nasabah dalam menggunakan internet banking berpengaruh terhadap keputusan dalam bertransaksi. Berdasarkan hasil analisis dapat diketahui variabel minat menggunakan internet banking memiliki pengaruh yang positif terhadap keputusan bertransaksi dengan menggunakan internet banking, yaitu semakin kuat minat menggunakan internet banking maka akan mengakibatkan keputusan bertransaksi dengan menggunakan internet banking 
semakin baik. Hasil penelitian ini ada kesesuaian dengan penelitian Prabowo (2007) dapat diketahui bahwa minat berpengaruh terhadap keputusan konsumen dalam bertransaksi.

Hipotesis ketujuh menyatakan minat nasabah dalam menggunakan internet banking dapat memediasi hubungan antara trust, risk and technology acceptance models dengan keputusan dalam bertransaksi dengan internet banking. Berdasarkan hasil analisis dapat diketahui minat dapat memediasi trust, risk, perceived case of use, dan perceived usefullnes dengan keputusan menggunakan internet banking, sedangkan variabel perceived of credibility tidak dapat dimediasi oleh minat terhadap keputusan menggunakan internet banking.

\section{PEMBAHASAN}

Hipotesis pertama menyatakan trust berpengaruh terhadap minat nasabah dalam menggunakan internet banking. Berdasarkan hasil analisis dapat diketahui terdapat pengaruh yang positif trust terhadap minat menggunakan internet banking. Hasil penelitian ini konsisten dengan penelitian Maharsi dan Fenny (2006) dapat diketahui kepercayaan pengguna pada internet banking (TRU) terbukti memberikan pengaruh yang signifikan terhadap loyalitas pengguna untuk menggunakan internet banking.

Hipotesis kedua menyatakan risk berpengaruh terhadap minat nasabah dalam menggunakan internet banking. Berdasarkan hasil analisis dapat diketahui variabel risk memiliki pengaruh yang negatif terhadap minat menggunakan internet banking, yaitu semakin tinggi risiko maka akan semakin rendah minat menggunakan internet banking. Hal ini berarti terdapat pengaruh negatif dan signifikan dari variabel risk terhadap minat menggunakan internet banking. Hasil penelitian ini ada kesesuaian dengan penelitian Lui dan Jamieson (2003) dapat diketahui perceived risk memiliki pengaruh terhadap intensitas untuk bertransaksi.

Pengujian hipotesis ketiga dan keempat merupakan pengembangan dari hasil penelitian Lui dan Jamieson (2003) dapat diketahui perceived case of use dan perceived usefullnes memiliki pengaruh terhadap intensitas untuk bertransaksi. Hipotesis ketiga dan keempat tersebut adalah perceived case of use berpengaruh terhadap minat nasabah dalam menggunakan internet banking dan perceived usefullnes berpengaruh terhadap minat nasabah dalam menggunakan internet banking. Berdasarkan hasil analisis dapat diketahui perceived case of use memiliki pengaruh yang positif terhadap minat menggunakan internet banking, yaitu semakin baik perceived case of use maka akan mengakibatkan minat menggunakan internet banking semakin tinggi. Hasil penelitian ini juga menghasilkan kesimpulan terdapat pengaruh positif dari variabel perceived usefullnes terhadap minat menggunakan internet banking, artinya semakin baik perceived usefullnes, maka minat menggunakan internet banking juga akan semakin kuat.

Hipotesis kelima menyatakan perceived of credibility berpengaruh terhadap minat nasabah dalam menggunakan internet banking. Berdasarkan hasil analisis dapat diketahui terdapat pengaruh positif dan signifikan dari variabel perceived of credibility terhadap minat menggunakan internet banking. Hasil penelitian ini ada kesesuaian dengan penelitian Maharsi dan Fenny (2006) dapat diketahui Kepercayaan pengguna pada Perceived of credibility terbukti memberikan pengaruh yang signifikan terhadap loyalitas pengguna untuk menggunakan internet banking.

Hipotesis keenam menyatakan minat nasabah dalam menggunakan internet banking berpengaruh terhadap keputusan dalam bertransaksi. Berdasarkan hasil analisis dapat diketahui variabel minat menggunakan internet banking memiliki pengaruh yang positif terhadap keputusan bertransaksi dengan menggunakan internet banking, yaitu semakin kuat minat menggunakan internet banking maka akan mengakibatkan keputusan bertransaksi dengan menggunakan internet banking semakin baik. Hasil penelitian ini ada kesesuaian dengan penelitian Prabowo (2007) dapat diketahui bahwa minat berpengaruh terhadap keputusan konsumen dalam bertransaksi.

Hipotesis ketujuh menyatakan minat nasabah dalam menggunakan internet banking dapat memediasi hubungan antara trust, risk and technology acceptance models dengan keputusan dalam bertransaksi dengan internet banking. Berdasarkan hasil analisis dapat diketahui minat dapat memediasi trust, risk, perceived case of use, dan perceived usefulness dengan keputusan menggunakan internet banking, sedangkan variabel perceived of credibility tidak dapat dimediasi oleh minat terhadap keputusan menggunakan internet banking.

\section{KESIMPULAN}

Kesimpulan dari penelitian ini berdasarkan hasil pembahasan di atas, adalah sebagai berikut: 1. Trust berpengaruh terhadap minat nasabah dalam menggunakan internet banking. 
2. Risk berpengaruh terhadap minat nasabah dalam menggunakan internet banking.

3. Perceived case of use berpengaruh terhadap minat nasabah dalam menggunakan internet banking.

4. Perceived usefullnes berpengaruh terhadap minat nasabah dalam menggunakan internet banking.

5. Perceived of credibility berpengaruh terhadap minat nasabah dalam menggunakan interne banking.

6. Minat nasabah dalam menggunakan internet banking berpengaruh terhadap keputusa dalam bertransaksi.

7. Minat nasabah dalam menggunakan internet banking dapat memediasi hubungan antara trust, risk and technology acceptance models dengan keputusan dalam bertransaksi dengan internet banking.

\section{DAFTAR PUSTAKA}

Ainur Rofiq. 2007. Pengaruh Dimensi Kepercayaan (Trust) Terhadap Partisipasi Pelanggan E-Commerce. Tesis S2. FE Universitas Brawijaya Malang.

Ferdinand, Agusty.2005. Structural Equation Modeling. Edisi ketiga. BP UNDIP, Semarang

Imam Ghozali, 2009, Ekonometrika, Teori, Konsep dan Apllikasi dengan SPSS 17, Badan Penerbit Universitas Diponegoro, Semarang.

Lui Hung Kit dan Rodger Jamieson, 2003. Tritam: a model for integrating trust and risk perceptions in bussiness to consumer Electronic Commerce. 16 th Bled E-Commerce Conference e- Transformation, Slovenia.

Mukherjee, A. and Nath, P. 2003. A Model of Trust in Online Relationship Banking. The International Journal of Bank Marketing Bradford, 21 (1), 5. March 10, 2005. http://proquest.umi,com/pqdweb?

Shergill, G.S. and Li, B. 2005. Internet Banking-An Empirical Investigation Of Customer's Behaviour for online Banking in New Zealand(online). Agustust 5, 2005. http://www. Business.massey.ac.nz/commerce /research_outputs /2004/ 2004011.pdf.

Sri Maharsi dan Fenny. 2006. Analisis Faktor-Faktor Yang Mempengaruhi Kepercayaan dan Pengaruh Kepercayaan Terhadap Loyalitas Pengguna Internet Banking di Surabaya. http.petra.ac.id 30 November 2008.

Sri Maharsi dan Yuliani Mulyadi. 2007.

Faktor-Faktor yang Mempengaruhi Minat Nasabah Menggunakan Internet Banking dengan Menggunakan Kerangka Technology Acceptance Model (TAM). http.petra.ac.id 30 November 2008 